\title{
A decade study of the incidence and clinical analysis of ectopic pregnancy at a tertiary hospital in Eastern Nigeria
}

\author{
Jemima A. Chukwu' ${ }^{1 *}$, Ambrose E. Agulanna1, Izuchukwu A. Okafor ${ }^{1,2}$, \\ Agnes A. Nwakanma ${ }^{3}$, Blessing C. O. Osuji ${ }^{4}$
}

\author{
${ }^{1}$ Department of Anatomy, Nnamdi Azikiwe University, Anambra State, Nigeria \\ ${ }^{2}$ Department of Obstetrics and Gynecology, Pan African University of Life and Earth Science Institute (Including Health \\ and Agriculture), University of Ibadan, Nigeria \\ ${ }^{3}$ Department of Anatomy, Chukwuemeka Odumegwu Ojukwu University, Anambra State, Nigeria \\ ${ }^{4}$ Department of Medical Services, Nigerian Ports Authority, Delta State, Nigeria
}

Received: 22 December 2021

Accepted: 12 January 2022

\author{
*Correspondence: \\ Jemima A. Chukwu, \\ E-mail: ja.chukwu@stu.unizik.edu.ng
}

Copyright: (c) the author(s), publisher and licensee Medip Academy. This is an open-access article distributed under the terms of the Creative Commons Attribution Non-Commercial License, which permits unrestricted non-commercial use, distribution, and reproduction in any medium, provided the original work is properly cited.

\begin{abstract}
Background: Ectopic pregnancy (EP), a condition where a fertilized egg grows outside a woman's uterus, is a fertilityand life-threatening gynecological condition. This study aimed at determining the incidence of EP, clinical presentation, gestational age at presentation, risk factors and treatment modalities.

Methods: This study was conducted at St. Charles Borromeo specialist hospital, Onitsha, Nigeria (January 2009 to December 2018). Information were obtained from the hospital's medical records as retrieved from various wards. Data were analyzed using IBM SPSS, version 23, then presented as percentage in tables and figure.

Results: Out of 13,402 pregnancies recorded in this study, 119 were EPs giving an incidence of $0.89 \%$. 105 case notes were included in this study since they met the inclusion criteria. Majority of the women belonged to the age group of 26-30 years. Patients with EP presented more between 7-8 weeks of gestational age (40\%), though $7.6 \%$ were unsure of their last menstrual period. $80 \mathrm{EP}$ cases $(76.2 \%)$ were ruptured while $25(23.8 \%)$ were unruptured. The ectopic gestation occurred most at the ampulla (51.4\%) and more at the right side $(66.6 \%)$ than the left $(33.4 \%)$. Pelvic inflammatory disease $(30.4 \%)$ followed by prior abortion $(20.0 \%)$ were major predisposing risk factors. The most common clinical presentations were abdominal pain $(92.38 \%)$, amenorrhea $(57.14 \%)$ and vaginal bleeding $(51.42 \%)$. $85.7 \%$ had salpingectomy, $9.5 \%$ were medically managed.

Conclusions: EP remains a major gynecological emergency. Diagnosis before rupture could offer an opportunity for a successful medical management, thereby; minimizing morbidity and mortality.
\end{abstract}

Keywords: Ectopic pregnancy, Amenorrhea, Salpingectomy, Gestational age

\section{INTRODUCTION}

EP is a pregnancy in which a fertilized egg gets implanted in a site other than the endometrium of a woman's uterus. It is a life-threatening gynecological emergency, one of the leading causes of pregnancy-related death in the first trimester and a major concern to female fertility.,
Following the last three decades, the incidence of EP has increased nearly to the level of an epidemic disease with variations from country to country, region to region and even within the same geographical region. ${ }^{3,4}$ Globally, the incidence of EP ranges from $1.0 \%-2.0 \% .^{5} \mathrm{~A}$ review by Liskin reported that the highest incidence of EP from the 1960s to the mid-1980s was observed in African countries 
(between $0.5-2.3 \%$ of all live births). ${ }^{6}$ Recent studies in Nigeria revealed that the incidence of EP has increased to a range of $1.2 \%$ and $4.6 \% .^{7-9}$

This rising incidence of EP has been associated with some predisposing risk factors like pelvic inflammatory disease (PID), abortion, in vitro fertilization (IVF) and use of intrauterine devices (IUD). ${ }^{10}$ Other etiological risk factors have been reported to include history of previous ectopic pregnancy, endometriosis, infertility, tubal surgeries and sterilizations. ${ }^{11}$

Above $95 \%$ of EPs occur in the fallopian tube. ${ }^{12}$ Other sites where EP can occur includes ovaries, cervix, cesarean scar, broad ligament and abdominal cavity. ${ }^{11,13}$ Common symptoms of EP are lower abdominal pain, amenorrhea, vaginal bleeding and syncope attack..$^{1,3,12}$

The treatment of EP can be done either through surgery, expectant or medical management; howbeit, surgery remains the mainstay of treating ectopic pregnancy. ${ }^{14}$ The site of the ectopic gestation, clinical state of the patient, patient's wish and available facilities and technology are factors that can influence the treatment of EP. ${ }^{4}$ Expectant management is offered to asymptomatic patients with less than $100 \mathrm{ml}$ hemoperitoneum and $\beta \mathrm{hCG}$ of $<1000 \mathrm{IU} / 1$ while medical management is usually considered for clinically stable patient with minimal hemoperitoneum, $\beta \mathrm{hCG}$ of $<5000 \mathrm{IU} / 1$ and a sac that is less than $3.5 \mathrm{~cm} .{ }^{1,14}$

Early diagnosis of EP increases the chances of successful medical treatment, thereby minimizing morbidity, mortality and financial burden. This can be done with transvaginal ultrasound and serial quantitative serum $\beta$ hCG. ${ }^{2,12}$

\section{Aim}

The aim of the study was to determine the incidence, clinical presentation, gestational age at presentation, site of occurrence, individual predisposing risk factors and modalities of treatment for EP cases that presented at St. Charles Borromeo specialist hospital, Onitsha, Nigeria within a ten-year period.

\section{METHODS}

A retrospective study was carried out over a period of ten years (1 January 2009 to 31 December 2018). This study was done at St. Charles Borromeo specialist hospital, Onitsha, Anambra State, Nigeria. The hospital card numbers of women with EPs were traced from ante natal ward, gynecology ward, female surgical ward, theatre unit, accident and emergency unit. The patients' case notes were then retrieved from the hospital's medical records unit and archive. The labour ward register was used to identify the total number of pregnancies for the study period. The data collected was in respect to the following age, parity, marital status, gestational age at presentation, location of the ectopic gestation, clinical presentation, risk factors for the EP and mode of treatment.

Women that were registered for visitation, admitted to deliver and completed their treatment with the hospital within the period of 1 January 2009 to 31 December 2018 were included for this study. The inclusion criteria for medical management of ectopic pregnancy were hemodynamic stability, transvaginal ultrasound scan showing gestational sac of less than $4 \mathrm{~cm}$, serum $\beta \mathrm{hCG}$ level of $<10,000 \mu / \mathrm{ml}$ and absence of free fluid in the pelvic cavity.

Data was entered in Microsoft excel spreadsheet and analyzed using IBM statistical package for social science (SPSS) for Windows, version 23 (IBM Corporation, Armonk, New York, USA). The data was then analyzed with simple descriptive statistics and presented as percentages in tables and figure.

\section{RESULTS}

In our decade study period, there was a total number of 13,402 pregnancies, of which 119 patients were diagnosed of EP, giving an incidence of $0.89 \%$ (Table 1). Only 105 cases notes were included for this study since they had adequate information and met the inclusion criteria.

Table 2 shows the bio-demographic characteristics of patients with EP. The age distribution of women with EP ranged from 18 to 52 years with a mean age of 28.12 years. The peak age was between 26-30 years, accounting for $37.1 \%$. The parity ranged from nulliparous to the sixth parity. Thirty-seven women were nulliparous (35.2\%). $72.4 \%$ of the patients were married, $23.8 \%$ were single while $3.8 \%$ were divorced.

Within this study sample of 105 patients, 95 patients $(90.5 \%)$ underwent surgery and 10 patients $(9.5 \%)$ were medically managed. Ultrasonographic findings of the 95 patients that were surgically managed are shown in Table 3. Eighty patients $(84.2 \%)$ had ruptured EP, while fifteen patients $(15.8 \%)$ had unruptured ectopic cases. Late presentation was observed in more than half of these patients, forty-two patients $(44.2 \%)$ presented between seven and eight weeks of gestational age. EP occurred more at the ampulla region (51.6\%). Majority of the women had their ectopic gestation at the right side $(67.4 \%)$ than the left $(32.6 \%)$.

Then, all ten patients that were medically managed had unruptured cases of EPs as reported in Table 4. Eight $(80 \%)$ of these unruptured cases were diagnosed at an early stage ( $\leq 5$ weeks) while the two patients $(20 \%)$ with abdominal pregnancy presented greater than nine weeks of gestational age. EP occurred more at the ampulla region $(50 \%)$ and at the right side $(60 \%)$ than the left $(40 \%)$. Therefore, out of the 105 patients in general, more patients (40\%) presented with EP between seven and eight weeks 
of gestational age though $7.6 \%$ were unsure of their last menstrual period.

All the patients presented with more than one clinical complaint. Table 5 shows the distribution of the various combinations of clinical presentation. A classic triad of abdominal pain, amenorrhea and vaginal bleeding accounted for $20 \%$. The most common presenting symptoms were abdominal pain, seen in $97(92.38 \%)$ patients. This was followed by amenorrhea and vaginal bleeding seen in $60(57.14 \%)$ and $54(51.42 \%)$ patients, respectively.

Some patients had more than one risk factor that predisposed them to ectopic pregnancy as reported in Table 6. Risk factors were found in 91 (86.6\%) patients, others (14 patients) were unspecified (13.4\%). Pelvic inflammatory disease (PID) was the commonest associated risk factor $(30.4 \%)$. Other risk factors include prior abortion $(20.0 \%)$, multiple sexual partners $(10.5 \%)$, prior EP $(8.6 \%)$, endometriosis $(7.6 \%)$, smoking at the time of conception (6.7\%), history of infertility (5.7\%), use of IUD $(5.7 \%)$, tubal ligation and sterilization $(1.9 \%)$.

Figure 1 below depicts that a more significant number of patients with EP were treated by salpingectomy (85.7\%). Ten $(9.5 \%)$ patients were medically managed successfully with methotrexate therapy. Other modalities of treatment observed in our study includes cornual resection (1.9\%), cervical evacuation (1\%). Unfortunately, there was one case of maternal death $(0.9 \%)$ during our decade study period.

Table 1: Number of pregnancies and incidence of EPs.

\begin{tabular}{|llll|}
\hline Year & Number of pregnancies & Number of EPs & Incidence (\%) \\
\hline $\mathbf{2 0 0 9}$ & 1,241 & 22 & 1.77 \\
\hline $\mathbf{2 0 1 0}$ & 1,264 & 12 & 0.95 \\
\hline $\mathbf{2 0 1 1}$ & 1,386 & 12 & 0.87 \\
\hline $\mathbf{2 0 1 2}$ & 1,437 & 10 & 0.70 \\
\hline $\mathbf{2 0 1 3}$ & 1,437 & 4 & 0.28 \\
\hline $\mathbf{2 0 1 4}$ & 1,476 & 11 & 0.74 \\
\hline $\mathbf{2 0 1 5}$ & 1,454 & 6 & 0.41 \\
\hline $\mathbf{2 0 1 6}$ & 1,458 & 23 & 1.58 \\
\hline $\mathbf{2 0 1 7}$ & 1,168 & 10 & 0.86 \\
\hline $\mathbf{2 0 1 8}$ & 1,081 & 9 & 0.83 \\
\hline \hline Total & 13,402 & 119 & 0.89 \\
\hline
\end{tabular}

Table 2: Bio-demographic characteristics of the patients.

\begin{tabular}{|lll|}
\hline Characteristics & Number $(\mathbf{n = 1 0 5})$ & Percentage $(\%)$ \\
\hline Age (years) & 3 & 2.9 \\
\hline$\leq 20$ & 35 & 33.3 \\
\hline $21-25$ & 39 & 37.1 \\
\hline $26-30$ & 21 & 20.0 \\
\hline $31-35$ & 5 & 4.8 \\
\hline $36-40$ & 2 & 1.90 \\
\hline$\geq 41$ & & \\
\hline Parity & 37 & 35.2 \\
\hline 0 & 29 & 27.6 \\
\hline 1 & 22 & 21.0 \\
\hline 2 & 10 & 9.5 \\
\hline 3 & 3 & 2.9 \\
\hline 4 & 4 & 3.8 \\
\hline$\geq 5$ & & \\
\hline Marital status & 25 & 23.8 \\
\hline Single & 76 & 72.4 \\
\hline Married & 4 & 3.8 \\
\hline Divorced & & \\
\hline
\end{tabular}


Table 3: Ultrasonographic findings of patients that underwent surgery.

\begin{tabular}{|lll|}
\hline Findings & Number $(\mathbf{n = 9 5})$ & Percentage (\%) \\
\hline Ruptured & 80 & 84.2 \\
\hline Unruptured & 15 & 15.8 \\
\hline Ectopic site & & \\
\hline Ampulla & 49 & 51.6 \\
\hline Fimbrial & 15 & 15.8 \\
\hline Isthmus & 12 & 12.6 \\
\hline Ovarian & 5 & 5.3 \\
\hline Cornual & 2 & 2.1 \\
\hline Cervical & 4 & 4.2 \\
\hline Broad Ligament & 2 & 2.1 \\
\hline Interstitial & 3 & 3.2 \\
\hline Infundibula & 2 & 2.1 \\
\hline Fundus & 1 & 1.0 \\
\hline Side of ectopic pregnancy & & \\
\hline Right & 64 & 67.4 \\
\hline Left & 31 & 32.6 \\
\hline Gestational age (weeks) & & \\
\hline $5-6$ & 27 & 28.4 \\
\hline $7-8$ & 42 & 44.2 \\
\hline $9-10$ & 9 & 9.5 \\
\hline$\geq 11$ & 9 & 9.5 \\
\hline Unsure of date & 8 & 8.4 \\
\hline
\end{tabular}

Table 4: Ultrasonographic findings of patients that were medically managed.

\begin{tabular}{|c|c|c|}
\hline Findings & Number $(\mathrm{n}=10)$ & Percentage (\%) \\
\hline Ruptured & - & - \\
\hline Un ruptured & 10 & 100 \\
\hline \multicolumn{3}{|l|}{ Ectopic site } \\
\hline Ampulla & 5 & 50.0 \\
\hline Fimbrial & 3 & 30.0 \\
\hline Abdominal & 2 & 20.0 \\
\hline \multicolumn{3}{|c|}{ Side of ectopic pregnancy } \\
\hline Right & 6 & 60.0 \\
\hline Left & 4 & 40.0 \\
\hline \multicolumn{3}{|c|}{ Gestational age (weeks) } \\
\hline$\leq 5$ & 8 & 80.0 \\
\hline$>9$ & 2 & 20.0 \\
\hline
\end{tabular}

Table 5: Distribution of the various combination of clinical presentation of EP.

\begin{tabular}{|lll|}
\hline Symptoms & Number & Percentage (\%) \\
\hline Abdominal pain, amenorrhea & 10 & 9.5 \\
\hline Abdominal pain, amenorrhea, back pain & 6 & 5.7 \\
\hline Abdominal pain, amenorrhea, fever & 3 & 2.9 \\
\hline Abdominal pain, amenorrhea, nausea & 8 & 7.6 \\
\hline Abdominal pain, amenorrhea, vaginal bleeding & 21 & 20 \\
\hline Abdominal pain, amenorrhea, weakness & 6 & 5.7 \\
\hline Abdominal pain, dizziness, fever, vaginal bleeding, weakness & 3 & 2.9 \\
\hline Abdominal pain, dizziness, fever, nausea, vomiting & 13 & 12.4 \\
\hline Abdominal pain, fever, vaginal bleeding & 7 & 6.6 \\
\hline Abdominal pain, itching, vaginal discharge & 5 & 4.8 \\
\hline Abdominal pain, syncopal attack, vaginal bleeding & 6 & 5.7 \\
\hline
\end{tabular}




\begin{tabular}{|lll|}
\hline Symptoms & Number & Percentage (\%) \\
\hline Abdominal pain, vaginal bleeding & 9 & 8.5 \\
\hline Amenorrhea, vomiting, vaginal bleeding & 3 & 2.9 \\
\hline Amenorrhea, shoulder pain, vaginal bleeding & 3 & 2.9 \\
\hline Dizziness, fever, shock, vaginal bleeding & 2 & 1.9 \\
\hline Total & 105 & 100 \\
\hline
\end{tabular}

Table 6: Distribution of the various combinations of identifiable risk factors.

\begin{tabular}{|lll|}
\hline Risk factors & Number (n=105) & Percentage (\%) \\
\hline Prior abortion, multiple sexual partners & 3 & 2.9 \\
\hline Adhesiotomy & 2 & 1.9 \\
\hline Appendectomy & 3 & 2.9 \\
\hline Endometriosis & 4 & 3.8 \\
\hline History of infertility & 6 & 5.7 \\
\hline Multiple sexual partners & 3 & 2.9 \\
\hline Multiple sexual partners, smoking & 1 & 0.9 \\
\hline Multiple sexual partners, prior ectopic pregnancy & 2 & 1.9 \\
\hline Myomectomy & 3 & 2.9 \\
\hline Pelvic inflammatory disease (PID) & 17 & 16.1 \\
\hline PID, endometriosis & 4 & 3.8 \\
\hline PID, prior abortion & 4 & 3.8 \\
\hline PID, prior EP & 1 & 0.9 \\
\hline PID, multiple sexual partners & 2 & 1.9 \\
\hline PID, smoking at the time of conception & 2 & 1.9 \\
\hline PID, prior abdominopelvic surgery & 2 & 1.9 \\
\hline Prior EP & 6 & 5.7 \\
\hline Prior abortion & 14 & 13.4 \\
\hline Smoking at the time of conception & 4 & 3.8 \\
\hline Use of IUD & 6 & 5.7 \\
\hline Tubal ligation/sterilization & 2 & 1.9 \\
\hline Unspecified & 14 & 13.4 \\
\hline Total & 105 \\
\hline
\end{tabular}

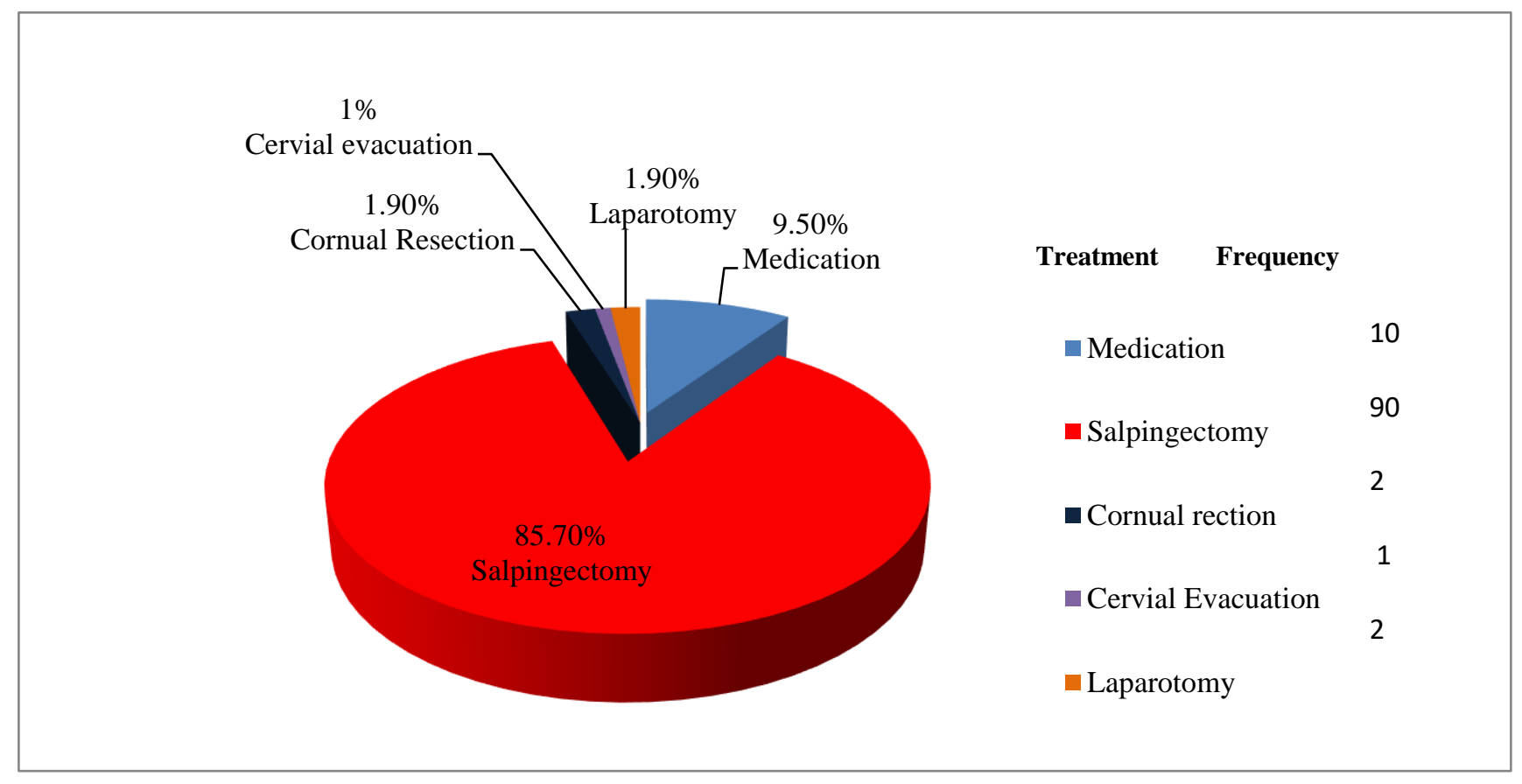

Figure 1: Mode of treatment for EP. 


\section{DISCUSSION}

EP is a gynecological emergency and its delayed diagnosis can endanger the patient's life and decrease the chances of future successful pregnancy. ${ }^{2,3,11}$ The incidence in our study centre was $0.89 \%$ of 13,402 pregnancies. A higher incidence was reported from similar studies carried out in Port Harcourt and Sokoto, both in Nigeria. ${ }^{7,15}$ This may be attributed to their larger population size and the predisposing risk factors of EP associated with various regions. ${ }^{16}$

In our study, majority of the patients with EP belonged to the age group of $26-30$ years (37.1\%). This was expected as it fell within the reproductive age and peak sexual activity. This report corresponded to the findings in Nnewi, Ebonyi, Port Harcourt, Kaduna, Sokoto, Abuja, all in Nigeria. ${ }^{1,-9,12,15,17,18}$ On the other hand, this finding contradicted with the findings in India where the highest peak age group was between 20-25 years. ${ }^{3,4,19}$ This could be related to the early marriage practiced in this part of the world. $^{20}$

Majority of the women with EP were nulliparous (35.2\%). In our findings, most of the patients with ectopic pregnancy were married (72.4\%). This finding contradicted some studies which reported that more single women presented with ectopic pregnancy than married women. ${ }^{7,16}$ This may be because these unmarried women were exposed to multiple sexual partners leading to more susceptibility of unintended pregnancies and subsequently, unsafe abortion or even a pelvic inflammatory disease after getting a sexually transmitted disease (STD) such as chlamydia or gonorrhea, which were some of the risk factors for EP. ${ }^{7,21}$

Some patients had more than one risk factor that may have predisposed them to ectopic pregnancy. PID (30.4\%) and prior abortion $(20.0 \%)$ were the most common risk factors identified from our study. This was similar to findings from other clinical centers in Nigeria. ${ }^{8,12,22}$ PID was as a result of ascending infections of the urinary tract that results in damage of the ciliated epithelium and formation of intra-mural adhesions and pockets. ${ }^{8}$ A consequence of these was the snare of the embryo or obstruction of the embryo transport and ectopic gestation; so, preventing these factors can reduce the occurrence of ectopic pregnancy and also the adverse effect on tubal patency. ${ }^{23}$

The study by Horne et al revealed a possible association between maternal smoking and EP. ${ }^{24}$ Interestingly, seven (6.7\%) patients in our study had history of smoking at the time of conception as predisposing risk factors. It was important to point out that smoke component alters the structure, function and epithelium of the fallopian tube, these changes may enhance the development of ectopic gestation. ${ }^{24}$ The effect of smoking can also kill or cause damage to the reproductive cilia thereby reducing the amount of time it took for a fertilized egg to reach the uterus. ${ }^{25}$ Hence, like other predisposing risk factors, women should avoid smoking at the time of conception even though the role it placed in EP was still unclear. ${ }^{24}$

In our study, all the women with EP had more than one symptom. Abdominal pain, amenorrhea and vaginal bleeding, as observed in our study, followed a global trend in the last few decades. ${ }^{26}$ The most common clinical presentation revealed in our study was a combination of abdominal pain, amenorrhea and vaginal bleeding accounting for $20 \%$. This combination was so similar to the $27.7 \%$ report from Abuja. ${ }^{8}$ These clinical presentations helped in easy diagnosis of EP in our centre, unlike in Ileife, Nigeria, where thirty-eight $(10 \%)$ patients were misdiagnosed initially at presentation resulting to five maternal deaths. ${ }^{27}$ Feelings of abdominal pain in any woman in child bearing age with amenorrhea and vaginal bleeding ought to create suspicion of EP. ${ }^{9}$

Our study was consistent with the global trend of EP cases occurring more on the right side $(66.7 \%)$ than the left $(33.3 \%)$. This could be due to infections prone to the right side from inflammation of the appendix. ${ }^{1}$ The ampulla region of the fallopian tube appeared to be the commonest site of occurrence of EP in our study. It accounted for $51.4 \%$, followed by the fimbrial end (17.1\%). Two (1.9\%) abdominal EPs was also observed in our study. This value was more than $0.6 \%$ as reported by Akaba et al 2012. ${ }^{8}$ This attested to the views that abdominal EP was a rare occurrence whose incidence could be difficult to estimate. $^{28}$

Unlike in developed countries where the unruptured EP cases were more common, our study revealed a high frequency of ruptured EPs. Eighty (76.2\%) patients had ruptured cases while the other twenty-five (23.8\%) patients had unruptured cases. This high number of ruptured cases was similar to $70.1 \%, 80.3 \%, 80.6 \%$ reported in Sokoto, Benin and Nnewi, all in Nigeria respectively. ${ }^{12,15,22}$ These could be attributable to the late presentation at the hospital and difficulty in early diagnosis. ${ }^{8}$

Our study revealed that the gestational ages of patients at presentation were within 7-8 weeks (40\%), though 7.6\% were unsure of their last menstrual period. Seven EP cases that presented at less than 4 weeks of gestational age in our study were included in the unruptured cases while those that presented above 6 weeks had a higher frequency of ruptured cases. The explanation on this could be that, as time goes on, the implanted embryo grew bigger at the ectopic site and the fetus became too large for the site at the late gestational age thereby causing a rupture. ${ }^{4}$ Hence, there was need for early diagnosis to prevent rupture. ${ }^{21}$ Also, the two (1.9\%) cases of abdominal EP that was medically managed in our study were unruptured cases. This happened to be unruptured cases probably because of the wide space in the abdomen and in most cases, rich blood supply. ${ }^{29}$ 
In our study, surgery remained the mainstay of treatment of EP. This was done mainly by salpingectomy. This study revealed that the $10(9.5 \%)$ early identified unruptured EP cases were successfully managed medically. This was done by systemic methotrexate therapy following diagnosis using transvaginal ultrasound. Assuming patients with EP presented on time before the rupture, they would have benefited from medical or expectant management. $^{12}$

In resource-poor settings like Africa, maternal mortality rate of $1-3 \%$ of all EP cases was 10 times higher than reported for industrialized countries. ${ }^{28}$ Unfortunately, there was a maternal death during our decade study accounting for a fatality rate of $0.9 \%$. This was lower than $5.7 \%$ and $2.5 \%$ reported in Oyo, Niger Delta, both in Nigeria. ${ }^{26,30}$ This could be attributable to late presentation, unawareness or a larger study population.

\section{Strengths and limitations of the study}

The strength of this study was that it provided significant findings needful to carry out future research, advance clinical practice and in planning future polices to properly manage EPs. Also, the very detailed analysis on the predisposing risk factors and clinical presentation were useful in creating precautionary awareness on EP.

Our study was limited by the form it took (retrospective), hence patients could not be followed up after treatment. This follow up would have been helpful to critically analyze the future fertility outcome or determine other predisposing clinical outcomes.

\section{CONCLUSION}

EP still remains a major gynecological emergency. Ruptured cases are life and fertility-threatening in women's health. The clinical triad of amenorrhea, abdominal pain and vaginal bleeding are commonest symptoms of EP. Pelvic inflammatory disease, prior abortion and multiple sexual partners are major risk factors that predisposes a woman to ectopic pregnancy as shown in this study. While surgery was the major treatment option available in this study, medical management was administered to patients diagnosed early of ectopic pregnancy. Therefore, it is recommended that relevant authorities should raise awareness on ectopic pregnancy. Pregnant women ought to register early for ante natal care and frequently go for routine medical check-up including ultrasound examinations. This will help in early diagnosis and proper treatment of ectopic pregnancy.

\section{ACKNOWLEDGMENTS}

The authors appreciate the director of administration, St. Charles Borromeo specialist hospital, Onitsha, Nigeria for granting us permission to carry out this research in their hospital. We appreciate the head nurse, head of records unit, Obiukwu Eugenia and staff of St. Charles Borromeo specialist hospital, Onitsha, Nigeria for their co-operation during data retrieval from various wards. Many thanks to the senior apostle Onwuka's family for providing housing during the period of data collection.

\section{Funding: No funding sources}

Conflict of interest: None declared

Ethical approval: The study was approved by the Institutional Ethics Committee

\section{REFERENCES}

1. Udigwe GO, Umeononihu OS, Mbachu II. Ectopic pregnancy: A 5 year review of cases at Nnamdi Azikiwe university teaching hospital (NAUTH) Nnewi. Niger Med J. 2010;51(4):160-3.

2. Zhang J, Zhang Y, Gan L, Liu X, Du S. Predictors and clinical features of methotrexate (MTX) therapy for ectopic pregnancy. BMC Pregnancy Childbirth. 2020;20(1):654.

3. Patel M, Chavda D, Prajapati S. A retrospective study of 100 cases of ectopic pregnancy: clinical presentation, site of ectopic and diagnosis evaluation. Int J Reprod Contracept Obstet Gynecol. 2016;5(12):4313-6.

4. Bhuria V, Nanda S, Chauhan M, Malhotra V. A retrospective analysis of ectopic pregnancy at a tertiary centre; one year study. Int $\mathrm{J}$ Reprod Contracept Obstet Gynecol. 2016;5(7):2224-7.

5. Barnhart KT. Clinical practice. ectopic pregnancy. N Engl J Med. 2009;361(4):379-87.

6. Liskin LS. Maternal morbidity in developing countries: a review and comments. Int J Gynecol Obstet. 1992;37(2):77-87.

7. Celestine OJ, Justina OA. Ectopic pregnancy experience in a tertiary health facility in South-South Nigeria. Niger Health J. 2016;16(1).

8. Akaba GO, Agida TE, Onafowokan O. Ectopic pregnancy in Nigeria's federal capital territory: a six year review. Niger J Med. 2012;21(2):241-5.

9. Oguejiofor CB, Ezugwu CJ, Eleje GU, Emeka EA. Ruptured ectopic pregnancy in a nigerian tertiary hosiptal: what has changed? Int J Gynecol Obstetric Res. 2020;8:14-9.

10. Rajkhowa M, Glass MR, Rutherford AJ, Balen AH, Sharma V, Cuckle HS. Trends in the incidence of ectopic pregnancy in England and Wales from 19661996. BJOG. 2002;107(3):369-74.

11. Anorlu RI, Oluwole A, Abudu OO, Adebajo S. Risk factors for ectopic pregnancy in Lagos, Niger. Acta Obstet Gynecol Scand. 2005;84(2):184-8.

12. Igwegbe AO, Eleje GU, Okpala BC. An appraisal of the management of ectopic pregnancy in a Nigerian tertiary hospital. Ann Med Health Sci Res. 2013;3(2):166-70.

13. Sorbi F, Sisti G, Pieralli A, Di TM, Livi L, Buccoliero $\mathrm{AM}$, et al. Cervicoisthmic choriocarcinoma mimicking cesarean section scar ectopic pregnancy. J Res Med Sci. 2013;18(10):914-7. 
14. Orazulike NC, Konje JC. Diagnosis and management of ectopic pregnancy. Women Health. 2013;9(4):37385 .

15. Panti A, Ikechukwu NE, Lukman OO, Yakubu A, Egondu SC, Tanko BA. Ectopic pregnancy at Usmanu Danfodiyo university teaching hospital Sokoto; a ten year review. Ann Niger Med. 2012;6(2):87-91.

16. Okoror CEM, Uhunmwangho BO, Idemudia O. Ectopic pregnancy at a teaching hospital, Nigeria: an analysis of presentation and risk factors. Menoufia Med J. 2020;33(2):415-8.

17. Lawani OL, Anozie OB, Ezeonu PO. Ectopic pregnancy: a life-threatening gynecological emergency. Int J Women's Health. 2013;19(5):51521.

18. Onwuhafua PI, Onwuhafua A, Adesiyun GA, Adze J. Ectopic pregnancies at the Ahmadu Bello university teaching hospital, Kaduna Northern Nigeria. Trop J Obstet Gynaecol. 2001;18(2):82-6.

19. Meena N, Bairwa R, Sharma S. Study of ectopic pregnancy in a tertiary care centre. Int $\mathbf{J}$ Reprod Contracept Obstet Gynecol. 2019;9(1):212-5.

20. Atlas. Fact sheet: Girls not brides. Available at: https://www.girlsnotbrides.org/child-marriage/india/. Accessed on 17 December 2021.

21. Abdulkareem TA, Eldan SM. Ectopic pregnancy: diagnosis, prevention and management. Intech. 2017:49-65.

22. Gharoro EP, Igbafe AA. Ectopic pregnancy revisited in Benin City, Nigeria: analysis of 152 cases. Acta Obstet Gynecol Scand. 2002;81(12):1139-43.

23. Kamwendo F, Forslin L, Bodin L, Danielson D. Epidemiology of ectopic pregnancy during a 28 year period and the role of pelvic inflammatory disease. Sex Transm Infect. 2000;76(1):28-32.

24. Horne AW, Brown JK, Nio-Kobayashi J. The association between smoking and ectopic pregnancy: Why nicotine is BAD for your fallopian tube. Plos One. 2014;9(2):89400.

25. Lynos RA, Saridogan E, Djahanbakhch O. The reproductive significance of human fallopian tube cilia. Hum Reprod Update. 2006;12(4):363-72.

26. Igberase GO, Ebeigbe PN, Igbekoyi OF, Ajufoh BI. Ectopic pregnancy: an 11-year review in tertiary center in the Niger Delta. Trop Doctor. 2005;35:1757.

27. Orji EO, Fasubaa OB, Adeyemi B, Dare FO, Onwudiegwu U, Ogunniyi SO. Motality and morbidity associated with misdiagnosis of ectopic pregnancy in defined Nigerian population. J Obstet Gynaecol. 2002;22:548-50.

28. Goyaux N, Leke R, Keita N, Thonneau P. Ectopic pregnancy in African developing countries. Acta Obstetricia et Gynecologica Scandinavica. 2003;82:305-12.

29. Paluku JL, Kalole BK, Furaha CM. Late abdominal pregnancy in a post-conflict context:case of a mistaken acute abdomen-a case report. BMC Pregnancy Childbirth. 2020;20(1):238.

30. Awojobi OA, Ogunsina S. Ectopic pregnancy in rural practice. Niger J Med. 2001;10:139-40.

Cite this article as: Chukwu JA, Agulanna AE, Okafor IA, Nwakanma AA, Osuji BCO. A decade study of the incidence and clinical analysis of ectopic pregnancy at a tertiary hospital in Eastern Nigeria. Int J Reprod Contracept Obstet Gynecol 2022;11:31522. 